ISSN: 1838-3815 (online) Journal Homepage: https://ojs.deakin.edu.au/index.php/itlge/

\title{
Provocation
}

Subject to Editor review, Provocations are intended to be short and showcase thought leadership and expert commentary on the future of credentials for work in a disrupted world.

\section{Micro-credentials: A learner value framework}

\author{
Beverley Oliver ${ }^{1}$ \\ Corresponding author: Beverley Oliver (b.oliver@deakin.edu.au) \\ ${ }^{1}$ Deakin University, Melbourne, Australia. ORCID: 0000-0002-2971-714X
}

\section{Introduction}

Much has been made of micro-credentials, and the 'craze' (Ralston, 2021) and 'hype' (Roy \& Clark, 2019) they generate. One of the barriers to their success is that a definition of micro-credentials has not been widely agreed (Kato, Galán-Muros, \& Weko, 2020). However, to succeed, micro-credentials need not just a definition, but a way to ensure they are valued, and bring value to key stakeholders: particularly learners, employers ${ }^{1}$ and providers. To this end, this provocation proposes a microcredential value framework that sets out their key benefits and costs for learners.

Gallagher asserts that a "more standardised taxonomy and a common language for naming, describing and communicating new forms of credentials would be helpful in accelerating adoption and ensuring value for both students and employers" (2016, p. 170, emphasis added). Some relevant micro-credential frameworks have been suggested: Oliver (2019) offers a simple typology to elucidate the main elements of micro-credentials (what they are intended to signify, where they are offered, and so on). Taxonomies of micro-credentials were investigated in Ifenthaler et al. (2016); however, these are predominantly concerned with badges, digital portfolios and interactive gaming.

On the topic of value, Rossiter and Tynan state that the micro-credential learner [first] enters a period of discovery, information gathering and understanding, exiting with a good grasp of the value proposition of the micro-credential (2019, p. 8, emphasis added). However, little research has been done to understand the common elements of such a value proposition, or indeed the actual value derived from a micro-credential. This provocation draws on the marketing literature: if a customer value proposition is a strategic tool that is used by a company to communicate how it aims to provide value to customers (Payne, Frow, \& Eggert, 2017, p. 467), then for micro-credentials, such a

\footnotetext{
${ }^{1}$ Not all micro-credentials are employment-related, but those that are need to be understood and valued by potential employers.
} 
definition might be reworded as 'a strategic tool that is used by an education provider to communicate how it aims to provide value to learners'.

\section{The framework}

The micro-credential learner value framework proposed here is based on the assumption that value is derived when the benefits of a credential are equal to or outweighed by the costs incurred in its attainment: that is,

\section{the VALUE of a micro-credential equals BENEFITS realised minus COSTS incurred.}

However, for learners, benefits and costs depend to some degree on an individual's motivation, circumstances and preferences: what one learner sees as a benefit (for example, challenging assessment), another might see as an imposition. To ensure they deliver expectations, providers should know and understand as much as feasible about the target learners' motivations, previous education, and circumstances, as shown in Table 1.

\section{Table 1: Learner Motivation, Education, Circumstances and Preferences that Influence Perceptions of Credential Value}

\begin{tabular}{|l|l|}
\hline \multirow{4}{*}{ Motivation } & Seeking to credential new skills or prior skills \\
\cline { 2 - 3 } & $\begin{array}{l}\text { Seeking a credential for career advantage (finding or securing work), or for personal } \\
\text { interest }\end{array}$ \\
\hline \multirow{5}{*}{ Education } & Previous educational qualifications \\
\cline { 2 - 2 } Qircumstances & Quality of previous educational experiences \\
\cline { 2 - 2 } & Eligibility re pre-requisites \\
\hline & Life stage \\
\cline { 2 - 2 } & Career stage \\
\cline { 2 - 2 } & Capacity to pay or secure funding \\
\cline { 2 - 2 } & Capacity to invest time in learning \\
\cline { 2 - 2 } & Capacity to engage in the mode of delivery (eg online, onsite) \\
\cline { 2 - 2 } & Competing obligations \\
\hline Preferences & Preference for mode of delivery, assessment type, peer engagement \\
\hline
\end{tabular}

Notwithstanding learner differences, this provocation proposes a framework (set out as Table 2) that maps the principal learner benefits and costs of engaging in micro-credentials. Learners are categorised as those seeking career advantage and those seeking personal interest learning (not all benefits and costs will apply equally to both types, and sometimes personal interest leads to career advantage and vice versa). The framework sets out eight headline benefits of micro-credentials: outcomes, certification, signalling power, interoperability with other credentials, quality and standards (including industry endorsement or accreditation, if relevant), assessment and feedback, engagement and convenience (whether the micro-credential can be achieved on demand, or not). These are weighed against the two costs: money and time (effort required, time lost in travel, and whether the learner could have been using their time more effectively). Comments and questions prompt the reader to understand what each of these might entail. 
Table 2: The Micro-credential Learner Value Framework

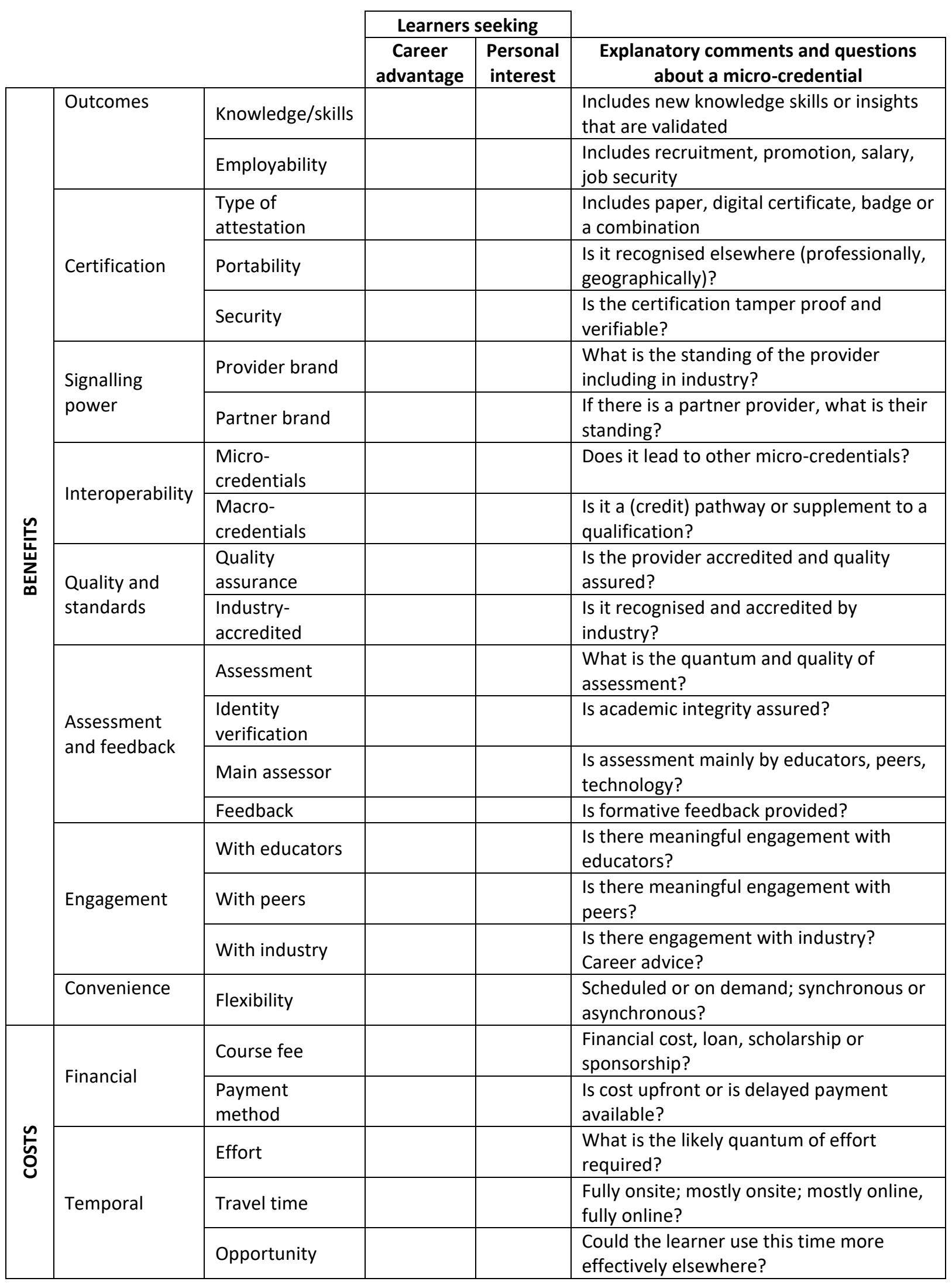

This provocation aims to be a conversation starter with regard to what a micro-credential learner value framework might entail, and more importantly, how it might be refined and used by providers to ensure maximum value, and thereby success, through micro-credentials. 


\section{References}

Gallagher, S. R. (2016). The future of university credentials: New developments at the intersection of higher education and hiring. Cambridge: Harvard education Press.

Ifenthaler, D., Bellin-Mularski, N., \& Mah, D.-K. (Eds.). (2016). Foundation of digital badges and microcredentials. Switzerland: Springer International Publishing.

Kato, S., Galán-Muros, V., \& Weko, T. (2020). The emergence of alternative credentials. Paris: OECD Publishing.

Oliver, B. (2019). Making micro-credentials work for learners, employers and providers. Melbourne: Deakin University. Available at: http://dteach.deakin.edu.au/microcredentials/

Payne, A., Frow, P., \& Eggert, A. (2017). The customer value proposition: evolution, development, and application in marketing. Journal of the Academy of Marketing Science, 45(4), 467-489.

Ralston, S. J. (2021). Higher Education's microcredentialing craze: a postdigital-Deweyan critique. Postdigital Science and Education, 3, 83-101. doi:10.1007/s42438-020-00121-8

Rossiter, D., \& Tynan, B. (2019). Designing and Implementing micro-credentials: A guide for practitioners. Commonwealth of Learning: Knowledge Series

Roy, S., \& Clark, D. (2019). Digital badges, do they live up to the hype? British Journal of Educational Technology, 50(5), 2619-2636. 